\title{
DOSSIER
}

\section{Lenguaje y Comunicación Digital}

\section{Resumen}

La rápida evolución de las nuevas llamadas tecnológicas en los últimos años también viene modificando las formas de comunicación en sus distintas manifestaciones, especialmente, en las redes sociales. Los distintos elementos que intervienen en este flujo, tanto emisores como receptores participan de la creación de nuevos códigos motivados u obligados por las condiciones en que se presenta el medio: nuevos formatos, velocidad, nitidez de pantalla, inmediatez y todo lo que genera estas características. Los elementos de la comunicación visual siguen intactos: textos, imágenes, sonidos, y todo lo que permite su materialización: color, movimiento, tipografía, etc. El lenguaje y la comunicación que se encuentran en este contexto son un desafío para quienes transitamos en el campo de la docencia universitaria, a medida que generaciones de migrantes y nativos digitales necesitan una forma común de compartir sus conocimientos.

Palabras Clave: Comunicación, lenguaje, nuevas tecnologías, educación.

\section{Language and Digital Communication}

\begin{tabular}{|c|c|}
\hline \multicolumn{2}{|l|}{ Abstract } \\
\hline The rapid evolution of new technology calls in the las & rears is also changing the \\
\hline $\begin{array}{l}\text { ways of communication in its various manifestations, } \\
\text { especially in social networks. The different elements } \\
\text { involved in this flow, both speakers and recipients, } \\
\text { participate in the creation of new codes motivated } \\
\text { or forced by the conditions presented in the media: } \\
\text { new formats, speed, screen sharpness, immediacy and } \\
\text { everything that generates these features. The elements } \\
\text { of visual communication don't change: texts, images, } \\
\text { sounds, and everything that allows its materialization: }\end{array}$ & $\begin{array}{l}\text { Arquitecto Luis Cumpa González } \\
\text { Docente de la Universidad } \\
\text { Nacional Mayor de San Marcos } \\
\text { y de la Universidad Femenina del } \\
\text { Sagrado Corazón. }\end{array}$ \\
\hline
\end{tabular}


color, motion, typography, etc. Language and communication found in this context are a challenge for those who are in the field of University teaching, as generations of migrants and digital natives need a common way to share knowledge.

Key words: Communication, language, new technologies, education.

La llegada de las tecnologías digitales viene transformando diversos campos de la comunicación, entre ellos las formas de elaboración de los contenidos verbales, visuales y multimediales. Esto ha generado una forma de comunicación distinta en algunos espacios de transmisión de la información que las tecnologías digitales ponen a disposición de millones de usuarios, como lo son, principalmente, las redes sociales caracterizadas por su manera de acceder a ellas (la movilidad de esos medios).

Presentamos algunas definiciones previas del concepto de comunicación y de lenguaje para tratar de comprender la relación con las TIC (Tecnologías de la Información y Comunicación) y el tema que estamos desarrollando.

La comunicación (humana), según Aurora Alonso " "es un proceso de interrelación social y cultural intencionado". También cita a Aristóteles: "...la retórica es el estudio de todos los medios de persuasión a nuestro alcance...", a Berlo: “...nos comunicamos para influir y para afectar intencionalmente...” y a Gallardo cuando señala: “...nadie se comunica por comunicarse...", todos ellos evidencian el carácter intencionado y utilitario de la comunicación y el lenguaje.

Igualmente, Alonso menciona:"los propósitos de la comunicación pueden ser muchos y variados, pero existen, fundamentalmente, tres tipos que están presentes desde siglos atrás: los de información, persuasión y entretenimiento y que no son excluyentes". Critica que "la comunicación en la educación no ha pensado mucho en la forma que se presenta el contenido suponiendo que el aprendizaje es suficiente gratificación y no tiene por qué divertir o agradar, incluso llega a utilizar el castigo y, a la vez, niega las posibilidades lúdicas o

${ }^{1}$ Alonso, Aurora (2004) Los medios de la Comunicación Educativa. México: Limusa. 
de goce estético porque no están en su intención explícita." Queda claro, que la forma, la retórica, la intencionalidad de los contenidos resultan ser de vital importancia en la comunicación, y veremos más adelante cómo esto se manifiesta de manera recurrente en la comunicación, particularmente a través de internet, en las redes sociales.

En relación con el Lenguaje, Saussure puso énfasis en el término sistema- Wulff ${ }^{2}$ y definió al lenguaje (lengua) "como un sistema de signos distintivos", la aparición del término comunicación tendrá un nuevo enfoque en la medida que consideran el lenguaje como un medio de comunicación que utiliza un sistema de simbolos" (Sapir, 1921).

Saussure, Hjelmslev, Martinet -menciona Wulff- reconocen la creatividad del lenguaje humano al sugerir, analizar y desarrollar el estudio del "proceso lingüistico que hace posible esa capacidad creadora".

De esta manera los signos lingüísticos, colores, formas, gestos, etc. articulados de distintas formas pueden dar lugar a un sinnúmero de variaciones y ofrecer posibilidades muy amplias para las formas de comunicación de estos tiempos.

Con estas definiciones, podemos ayudarnos a comprender otros aspectos que nos deben conducir a extraer utilidad de esta exposición

\section{Hitos de la Comunicación Humana}

La permanente búsqueda de mecanismos de comunicación entre los humanos motivados por la necesidad de supervivencia, ha llevado a registrar, probablemente desde sus inicios, señales, huellas, marcas, en piedras, árboles u objetos expresamente elaborados para tal fin, y progresivamente alcanzar niveles de creación fundamentales como la invención del alfabeto fonético, la invención de los tipos móviles y, desde hace una década, las denominadas nuevas tecnologías de información y comunicación basadas en el lenguaje digital.

${ }^{2}$ Wulff, Enrique (1981). Lenguaje y Lenguas. Barcelona: Salvat. 
Observemos en este devenir histórico el concepto de lo digital:

Se dice que el habla humana es el primer soporte, podrían haber sido también los gestos, pero como quiera que fuera, estos no podían ser fijados o registrados; la comunicación verbal tuvo durante mucho tiempo como único soporte la memoria de las personas.

La aparición de medios mecánicos o electrónicos que permiten registrar, grabar y reproducir las imágenes y los sonidos ha cambiado la manera de almacenar la información. Esto ha devenido en la verbalización o escritura sin las preocupaciones de cumplir con un "estándar académico" en algunos servicios de comunicación por internet (chat, redes sociales, skype) e incluso en algunos espacios públicos.

Aquí, es necesario considerar cada uno de los elementos del proceso de la comunicación (clásica) para tratar de comprender más adelante la implicancia en la generación de contenidos, formas de reproducción y maneras de consumir la información a través de las TIC.

Cuadro No. 1

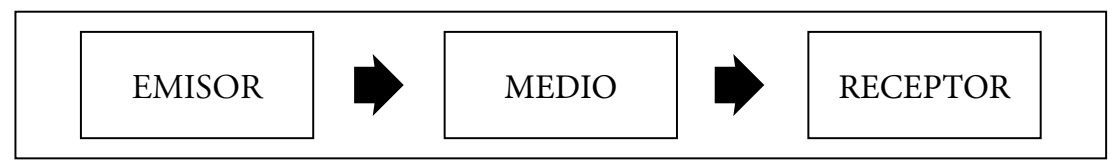

Como se observa en el cuadro No. 1, el gran transmisor, ahora, es la llamada nube que, como ya sabemos, no está en el espacio sino en lugares específicos de la tierra. Le dicen nube a simples servidores (almacenadores) de toda la información que se genera en las computadoras conectadas a internet en todo el mundo. Todo lo que se pueda crear en el mundo real y pueda digitalizarse en voz, música, dibujos, textos, videos, etc., y almacenarse en dicha nube, y que puede ser trasformado y consumido en cualquier lugar y momento.

¿A dónde nos conduce esto? Dependiendo del interés de cada quien: sea educador, tecnólogo, comunicador o un simple usuario, tendrá una manera diferente de generar, seleccionar y procesar la transmisión de contenidos. En lo que concierne al presente artículo, pretendemos 
señalar, desde el punto de vista de la comunicación, la necesidad de estudiar las nuevas formas de construir lenguajes que sintonicen con los nuevos medios por los que discurre la información. De esto volveremos a hablar más adelante.

\section{El Encuentro de la Comunicación con la Educación}

Introducimos aquí el tema de la educación no solo en su acepción reducida a la formación escolar básica sino al concepto como cultura. Alonso ${ }^{3}$ cita a los griegos: "... definieron la educación como la actividad que permite al hombre trascender su espacio y tiempo de vida. Por eso pusieron énfasis en el mejoramiento del lenguaje - de la retórica-necesario para poder explorar el mundo de las ideas..."

El concepto educación en relación con la comunicación cobra sentido por la presencia del lenguaje como recurso para manifestarse a través de sus distintas expresiones: oral, escrita, visual, auditiva o multimedial. De esta forma, nos encontramos frente a la necesidad de concebir la comunicación como el vehículo de la información que el o los modelos educativos desarrollan buscando el o los lenguajes apropiados para su cabal entendimiento.

A pesar de que, como apunta Alonso ${ }^{4} \ldots$ ambos nacen independientes y se desarrollan diferentes...", a la vez compara: "...la educación es una disciplina añeja... la permanencia de siglos en el pensamiento conservador ha generado una fuerte tendencia en tal sentido... en contraste, la comunicación es una disciplina muy joven... no obstante, su rápido desarrollo ha trascendido todos los ámbitos de la cultura y de la sociedad, removiendo las formas de entender y concebir el mundo..."

Esto ha ido ampliándose con la aparición de las TIC y su impacto global, a pesar de los detractores de McLuhan. La educación busca en esta disciplina su retórica para manifestarse, y los lenguajes se apropian

\footnotetext{
${ }^{3}$ Alonso, Aurora. Op cit.

${ }^{4}$ Alonso, Aurora. Op. cit.
} 
de esta. De ahí que la comunicación necesita contar con los elementos que le permitan discurrir no solo en forma oral o escrita, sino visual o multimedialmente con las características que el medio permite: la hipertextualidad, instantaneidad, interactividad y las nuevas posibilidades de visualización o captación de la información: la tridimensionalidad, la alta definición y la posibilidad de generar sensaciones de presencialidad a través de la inmersión y la virtualidad. Por aquí es que la educación encuentra a la comunicación como su aliada natural.

\section{La Creatividad como Aliada}

La idea de que la creatividad es una habilidad que se puede desarrollar es reciente "... se ha venido rompiendo el mito de los genios renacentistas, el paradigma: ... don atribuido a unos pocos elegidos", apunta Parra ${ }^{5}$ que considera a la creatividad como un área de la psicología. Es lógico pensar que el hombre de la prehistoria ha tenido que ser creativo para sobrevivir y permanentemente crear mecanismos para lograr la progresiva mejora de sus condiciones de vida: verbalización, graficación, etc. Solo en lo que se refiere a la imagen': “...dibujos de color ocre en huesos, 30,000 años a C... composiciones radiantes en Lascaux, 15,000 a. C... cráneos de órbitas realzadas con hematites, 5,000 a. C... etc." además de la invención de la escritura, el papel, la imprenta de tipos móviles por Gutemberg, la fotografía, el teléfono, la televisión y tantos otros que expresan la capacidad humana para crear. Pero, la creatividad también está asociada a la simple capacidad para resolver un problema de diferentes formas, de muchas formas, de originales formas, características ampliamente tratadas por los especialistas, así como la teoría de las inteligencias múltiples de Gardner y los conceptos de convergencia y divergencia en el proceso creativo.

Nos interesa destacar este aspecto de la creatividad para afirmar que la comunicación puede nutrirse de manera creativa con nuevos lenguajes; es el reto que le propone la aparición permanente de tecnologías y las nuevas maneras de comunicación individual o grupal.

5 Parra Duque, Diego (2003). Creativamente. Colombia. Norma.

${ }^{6}$ Debray, Regis (1992). Vida y Muerte de la Imagen. Barcelona. Paidos. 
Los fabricantes de tecnologías inventan los dispositivos y nos muestran sus atributos, pero los lenguajes corresponden a quienes generan los contenidos en función de los consumidores de los mismos. Aquí radica lo central de este artículo.

\section{Las llamadas Nuevas Tecnologías de Información y Comunicación}

La aparición de nuevas tecnologías en el campo de la comunicación e información exige una mirada a las formas cómo se procesa la información, el mecanismo de transmisión y la manera de recibirla y decodificarla. El lenguaje atraviesa todos estos momentos: elaboración, transmisión, decodificación e interpretación, en las que se incluyen el texto, la voz, el sonido, la imagen, lo audiovisual y lo multimedial.

Asistimos en estos tiempos a la aparición de tecnologías que inducen a comportamientos sociales nuevos que se manifiestan en la realidad y la virtualidad. En la realidad, la posibilidad de comunicarse pasa, por un trasmisor móvil y, aunque están presentes los actores, en una reunión, por ejemplo, la comunicación trasciende el espacio físico de ese momento, esta fascinación por el contacto a distancia en estas condiciones expresa la segunda manifestación: la virtualidad, donde el contacto no está presente físicamente pero existe en la virtualidad que puede ser acogida individual o grupalmente. Solo mencionamos el hecho. Por ahora, nos interesa observar lo que fascina: la inmediatez, la interactividad, la capacidad de transgresión del espacio en la comunicación. Dejaremos para otro estudio los factores que generan esta fascinación.

\section{El Lenguaje Total}

Efectivamente, como señala Alonso7: “...desarrollada por Antoine Vallet en la década de los 50 -el lenguaje de nuestra época es el lenguaje total - palabras imágenes y sonidos- el lenguaje de todo el hombre y de todos los medios de comunicación ... ", ahora llamamos multimedial a esa totalidad,

7 Alonso, Aurora. Op. cit. 
pero queda entendido que la gestualidad, lo kinésico, lo proxémico son otros aspectos que pertenecen a esta totalidad.

De acuerdo con lo mencionado anteriormente, convenimos que el concepto de lenguaje es entendido en una dimensión muy amplia, no solo lo relacionado con las TIC, sino con las expresiones externas que se han mencionado aquí. Siendo así, la tarea para quienes producen los mensajes pasa por el conocimiento de las tecnologías en todos sus componentes: hardware/software, sus cualidades, su funcionamiento y sus lenguajes en el proceso de la comunicación.

Cuando se habla del lenguaje total, se asume la necesidad de que el creador de contenidos conozca no solo el aspecto tecnológico, sino también la forma cómo los consumidores del mensaje se comunican, lo que implica que es necesario involucrarse con la cultura del lenguaje que se está generando.

Para los nacidos antes de la aparición de las TIC (lo digital), el paradigma del manejo de la información es lineal, heredada de la cultura de la gran revolución de los tipos móviles, desarrollado por Juan Gutemberg.

Las tecnologías electrónicas como la radio y la televisión crean sus propias maneras de materializar el mensaje mediante la operación de esos equipos con botones de giro izquierda/derecha o arriba/abajo; son modificadas con la aparición de los ordenadores con dispositivos que cambian totalmente el paradigma de presentación y manejo de los equipos tanto en el propio aparato como en el contenido que proveen. La sola presencia del mouse como extensión de la mano para escribir o graficar implica una modificación en las formas de operación de este recurso tecnológico. Hoy, vemos que este mouse va desapareciendo para crear el mouse invisible que no viene a ser sino la proyección de unas ondas sobre la zona de la mano que permite hacer las mismas operaciones con los dedos, o la tecnología "blue tooth" que permite, mediante el tacto, operar ordenadores y celulares.

Esta concepción del paradigma en la utilización de los objetos ya fue estudiada por $\mathrm{Eco}^{8}$, cuando pone el ejemplo de la rampa como paradigma para ascender en un terreno, que luego evolucionaría a la forma de escalera

8 Eco, Umberto (2011). La estructura ausente. México: De bolsillo. 
para, en los últimos tiempos, variar totalmente con la aparición de los ascensores, tecnología que requería entender que el ascenso se producía solo presionando un botón, para ingresar a la caja que ha de transportar hasta el nivel respectivo.

Pero, más allá de la capacidad para la operación de estos equipos en su componente material (hardware), los creadores de contenidos tienen la obligación de conocer el nuevo paradigma de la lectura (o consumo) de la información en las TIC, que implica conocer los conceptos de: hipertexto, hipermedia, multimedia, interactividad, conectividad, inmersión, realidad virtual, etc. De todos ellos, el concepto de hipertexto es el más destacable.

El hipertexto modifica totalmente el paradigma de la lectura de la información. Este ya no es lineal, ya no es de izquierda a derecha, ya no es de arriba abajo, ya no tiene una duración específica y requiere que en cada sección de la información los "lenguajes parciales" de la información sean entendidos en el contexto del lenguaje general de una información hipermedia, por ejemplo. El texto, la imagen, la imagen en movimiento, el sonido y todas las capacidades de interacción de cada uno de ellos deberán ser concebidos para ser entendidos con este nuevo paradigma.

La característica del hipertexto, por citar una muestra, cambia la linealidad de la lectura, no alterada desde la invención de los tipos móviles, en la medida que el click en la palabra vinculada la transporta, al instante, a ese nuevo sitio con nueva información que puede estar en lugares muy lejanos, así como la posibilidad de obtener una respuesta por parte de alguien (interactividad).

Esto es lenguaje, nuevo lenguaje en las TIC El formato de las pantallas de lectura de los dispositivos empiezan a exigir nuevas formas de concebir los contenidos: el color y la tipografía, ambos compitiendo en legibilidad. Hoy, la pregunta es: qué poner en una pantalla de pequeñas dimensiones y posiblemente para un consumo instantáneo, cómo pensar la imagen en ultra alta definición de pantallas grandes y, posiblemente, para un consumo basado en la contemplación. La generación de contenidos se vuelve especializada. Los elementos de la comunicación visual se mantienen: forma, color y concepto. Cambian el soporte, el lenguaje, la articulación de los elementos en función de la hipermedialidad y otras características ya mencionadas. 
Las implicancias de las tecnologías digitales en la construcción de nuevos lenguajes en el proceso de comunicación trascienden las pequeñas pantallas de los dispositivos móviles o de las grandes en ultra alta definición; esta trascendencia se encuentra en otro lugar, se encuentra en los lugares de formación de quienes generarán contenidos profesionalmente. El nuevo paradigma del diario, del folleto, del cartel, de la historieta, del anuncio, etc. es el reto de los generadores de contenido para el soporte digital. Se tiene que crear nuevos formatos, nuevos códigos, nueva forma de uso de los signos del alfabeto, nueva relación con el hardware (pantalla táctil, voz, plegado del soporte, etc.). Sin embargo, el desafío es primero para quienes estudian los principios de la comunicación digital; el monitoreo permanente de la aparición de nuevos soportes y su forma de recibir y transmitir el mensaje es una obligación si se pretende tener vigente el carácter funcional de la comunicación.

A manera de conclusión: el nuevo lenguaje a partir de la aparición de las TIC implica la superación de la linealidad de la lectura; los elementos clásicos de la comunicación visual (color, punto, línea, proporción, movimiento, etc.); adquieren nuevos comportamientos en su uso: modificación permanente de los soportes (táctiles, sintéticos y plegables, virtuales, etc.); el consumidor de los mensajes con una cultura de códigos muy referida a estas tecnologías, fundamentalmente en las generaciones denominadas nativas digitales; aparición de nuevas posibilidades en la legibilidad de los mensajes (UHDTV, 3D); adecuación del mensaje al formato del nuevo soporte, y, finalmente, en este panorama, tratar de que los nativos digitales y los que migraron puedan encontrarse y entenderse. 
Alonso, Aurora. (2004). Los Medios en la Comunicación Educativa. Limusa. México.

Debray, Regis (1992). Vida y Muerte de la Imagen. Paidos. Barcelona. Dondis, Donis A. (1995). La Sintaxis de la Imagen. G. gili. México. Eco, Umberto (2011). La estructura ausente. Debolsillo. México García Canclini, Néstor. (2012). La Globalización Imaginada. Paidós. México.

García Yruela, Jesús. (2003). Tecnología de la Comunicación e Información Escrita. Síntesis. Madrid.

Mouchard, Teresa.(1998). Introducción a la Comunicación. Cap. El Proceso de la Comunicación. Fondo de Desarrollo editorial Universidad de Lima. Perú.

Parra Duque, Diego (2003). Creativamente. Norma. Colombia. Wulff, Enrique (1981). Lenguaje y Lenguas. Salvat. Barcelona. Zechetto, Victorino. (2010) La Danza de los Signos. La Crujía. Buenos Aires. 
